\title{
Interaction of cis-1,4-Dinitroglycoluril and its Isomers with Magnesium-A DFT Treatment
}

\section{Lemi Türker}

Department of Chemistry, Middle East Technical University, Üniversiteler, Eskişehir Yolu No: 1, 06800 Çankaya/Ankara, Turkey; e-mail: lturker@gmail.com; lturker@metu.edu.tr

\begin{abstract}
cis-1,4-Dinitroglycoluril, known as DINGU, is an insensitive explosive. To investigate the compatibility of it and its nitramine isomers with magnesium, some model composites of them have been subjected to density functional treatment at the level of B3LYP/6$31++\mathrm{G}(\mathrm{d}, \mathrm{p})$. Within the restrictions of the theory and the level of calculations performed, it has been found that most of the composites considered are unstable and undergo $\mathrm{N}-\mathrm{NO}_{2}$ bond rupture. Moreover, it has been in one case found that the elongation of nitramine bond is dictated by the way of approach of the $\mathrm{Mg}$ atom to the organic component. Some physical and molecular orbital properties of the systems are obtained and discussed.
\end{abstract}

\section{Introduction}

The date of synthesis of nitrourea explosives goes back to 1974. N-nitroureas are very attractive because mono-nitroureas and di-nitroureas were proved to have a good explosive performance. Some N-nitroureas such as TNGU and 1,4-dinitroglycouril (DINGU) are to be mentioned. An explosive that has been of interest to the HEMs (high energy materials) community recently is cis-1,4-Dinitroglycoluril (cis-DINGU) [1-3]. It is an important explosive. cis-DINGU was first prepared as early as 1888 by Franchimont and Klobbie [4, 5].

Afterwards the synthesis of cis-DINGU and its derivatives were described in the literature [6-8]. cis-DINGU is regarded as one of the potential ingredients for low

Received: January 30, 2020; Accepted: March 20, 2020

Keywords and phrases: cis-1,4-Dinitroglycoluril, DINGU, explosives, magnesium, DFT.

Copyright (C) 2020 Lemi Türker. This is an open access article distributed under the Creative Commons Attribution License, which permits unrestricted use, distribution, and reproduction in any medium, provided the original work is properly cited. 

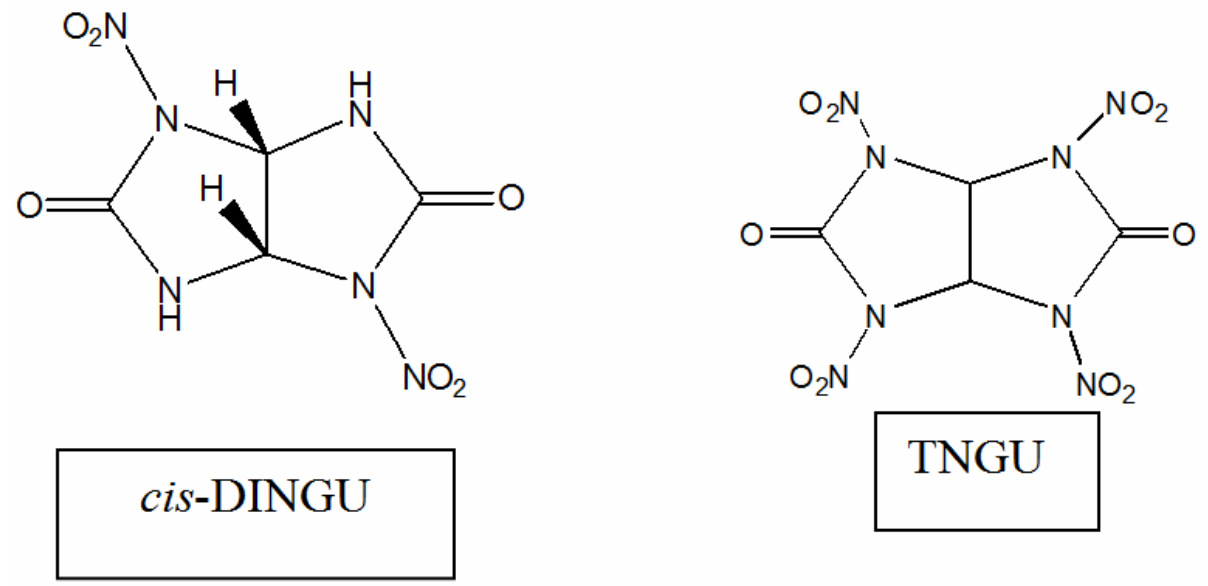

vulnerability ammunition (LOVA) applications [9]. cis-DINGU is an insensitive material which has been an alternative to RDX (hexahydro-1,3,5-trinitro-s-triazine) and TNT (trinitro-toluene) [10]. cis-DINGU based polymer bonded explosives (PBXs) are prepared which possess high explosion energy, good physico-chemical stability and low vulnerability. Because of all these properties cis-DINGU is comparable to TATB (triamine-trinitro-benzene)-based PBXs. Note that the preparation of cis-DINGU is very simple and requires inexpensive starting materials as compared to TATB. Therefore, cisDINGU based PBXs are highly preferable over TATB based PBXs [11]. Also toxicological hazards of cis-DINGU were investigated [12] and according to the classical guidelines, it would be considered only slightly toxic. The literature, contains many studies on cis-DINGU including its synthesis [6-8], structure determination (X-ray diffraction for cis-DINGU) [13], evaluation of the solid-state formation enthalpy [14], spectro-thermal decomposition [15], mass-spectral fragmentation pathways [16]. Some of the studies have concentrated on modelization by molecular mechanics [17] and modelization by using AM1and PM3 methods [18]. A computational study performed using DFT and ab initio methods which revealed some structural, quantum chemical and thermal properties of DINGU configurational isomers (cis-and trans- DINGU) in the gas phase [19]. Some DFT calculations even on trans-dinitroglycoluril isomers have been published [20]. However, to the best of the knowledge of the author, there is no study on interaction of metals with cis-DINGU. In the present study, interaction of magnesium with cis-DINGU isomers has been investigated within the constraints of density functional theory (DFT). 


\section{Method of Calculation}

The geometry optimizations of all the structures presently considered, leading to energy minima were achieved first by using MM2 method [21, 22] for the equilibrium conformer. Subsequent optimizations were achieved at Hartree-Fock level using various basis sets hierarchically. Then, the geometry optimizations were managed within the framework of density functional theory [23, 24], finally at the levels of RB3LYP /6$31++G(d, p)$. Note that the exchange term of B3LYP consists of hybrid Hartree-Fock and local spin density (LSD) exchange functions with Becke's gradient correlation to LSD exchange $[24,25]$. Note that the correlation term of B3LYP consists of the Vosko, Wilk, Nusair (VWN3) local correlation functional [26] and Lee, Yang, Parr (LYP) correlation correction functional [27]. The vibrational analyses have also been done. The total electronic energies are corrected for the zero point vibrational energy (ZPE). The stationary points to energy minima were proved in all the cases by calculation of the second derivatives of energy with respect to the atom coordinates. The normal mode analysis for each structure yielded no imaginary frequencies for the $3 \mathrm{~N}-6$ vibrational degrees of freedom, where $N$ is the number of atoms in the system. This indicates that the structure of each system corresponds to at least a local minimum on the potential energy surface. All these calculations were done by using the Spartan 06 package program [28].

\section{Results and Discussion}

DINGU structure has two configurational isomers, cis- and trans-DINGU. Of those cis-DINGU is in use as an explosive material.

Magnesium atom has $1 s^{2} 2 s^{2} 2 p^{6} 3 s^{2}$ electronic configuration in its ground state. It is a closed shell system and donating its $3 \mathrm{~s}$ electrons it may reduce certain organic functional groups. Magnesium atom also forms some organomagnesium compounds, such as Grignard compounds, most of them exhibit spontaneous ignition in air and makes them difficult to handle [29]. The ionization potential of magnesium is $7.61 \mathrm{eV}$ and $14.96 \mathrm{eV}$, respectively for the first and second oxidation states [30].

Figure 1 shows the constitutional isomers of cis-DINGU. Isomer-A differs from the others because two of the nitramine moieties are possessed by the same pentagonal ring. 

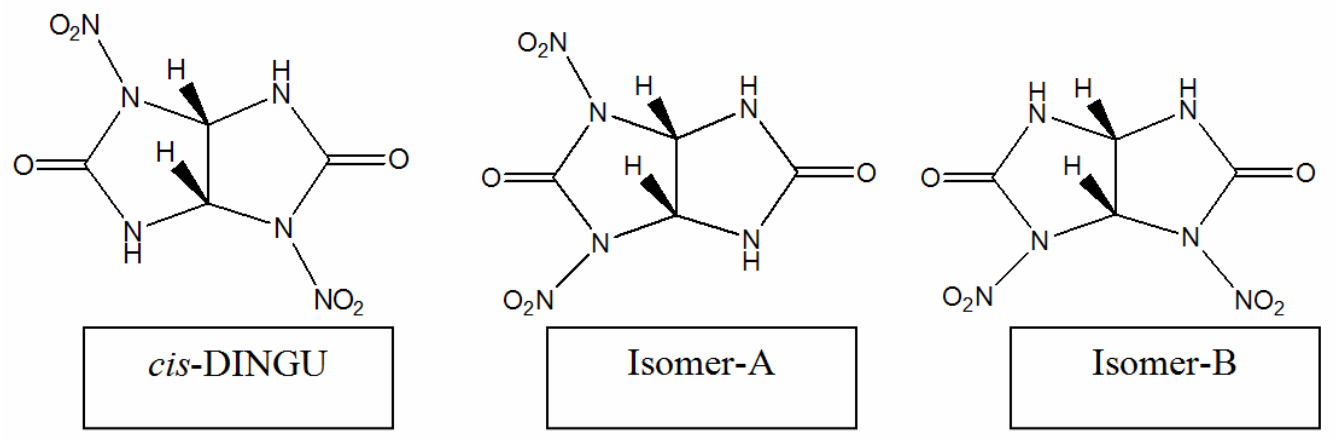

Figure 1. cis-DINGU and its isomers considered.

Figure 2 shows the optimized structures of the cis-DINGU+Mg composites
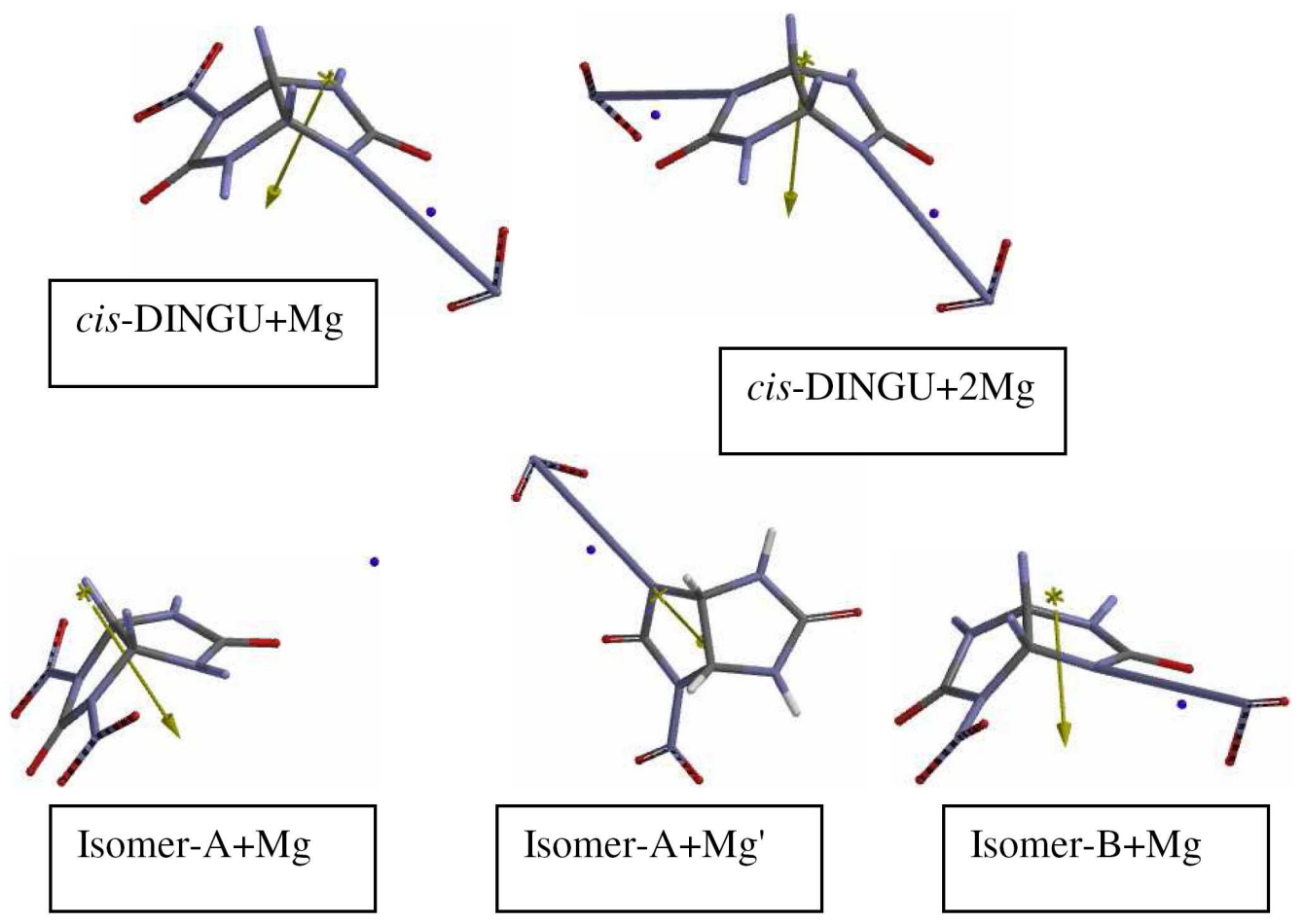

Figure 2. Optimized structures of the composites considered.

considered. As seen in the figure, cis-DINGU+ Mg and cis-DINGU+ $2 \mathrm{Mg}$ composites are not stable and undergo one and two $\mathrm{N}_{-} \mathrm{NO}_{2}$ bond cleavages, respectively. On the other hand, isomer- $\mathrm{A}+\mathrm{Mg}$ composite seems to be stable whereas isomer- $\mathrm{A}+\mathrm{Mg}$ is 
unstable. Note that the difference between composites labeled as isomer- $\mathrm{A}+\mathrm{Mg}$ and isomer- $\mathrm{A}+\mathrm{Mg}^{\prime}$ is the location of the $\mathrm{Mg}$ atom. In isomer- $\mathrm{A}+\mathrm{Mg}$ case the $\mathrm{Mg}$ atom approaches the organic component from the embedded urea moiety which does not have any nitramine group in contrast to isomer $-\mathrm{A}+\mathrm{Mg}$ ' case where $\mathrm{Mg}$ atom approaches from the site of nitramine moieties. Isomer- $\mathrm{B}+\mathrm{Mg}$ composite is unstable and undergoes $\mathrm{N}-\mathrm{NO}_{2}$ bond rupture irrespective of from where the $\mathrm{Mg}$ atom approaches. Both of isomers-A and -B cannot bear two $\mathrm{Mg}$ atoms just at the initial construction stage. So, their optimizations could not be carried out.

Figure 3 displays the bond lengths of the structures of present concern. Note that in the decomposed composites $\mathrm{C}=\mathrm{O}$ bond length of the ring having $\mathrm{N}-\mathrm{NO}_{2}$ bond is 1.27 $1.28 \AA$. Whereas their other $\mathrm{C}=\mathrm{O}$ bonds is about $1.20 \AA$. In the stable isomer- $\mathrm{A}+\mathrm{Mg}$ composite the $\mathrm{C}=\mathrm{O}$ bond lengths are $1.22 \AA$ and $1.19 \AA$. The last value belongs to $\mathrm{C}=\mathrm{O}$ bond of the ring having two of the nitramine groups. Elongation of the $\mathrm{C}=\mathrm{O}$ bond of the ring(s) having ruptured $\mathrm{N}-\mathrm{NO}_{2}$ bond(s) indicate that some electron population has been delocalized over the carbonyl group(s). Note that in isomer-A+ Mg composite, which is stable, the location of $\mathrm{Mg}$ atom is quite distant from the organic component.

Figures 4 and 5 stand for the ESP and natural charges on the atoms of the structures considered, respectively. Note that the ESP charges are obtained by the program based on a numerical method that generates charges that reproduce the electrostatic potential field from the entire wavefunction [28]. In all the cases $\mathrm{Mg}$ atom acquires some partial positive charge. All the expelled $\mathrm{NO}_{2}$ moieties have partial overall negative charges.

IR spectra of the composite structures considered are shown in Figure 6. The sharp peaks around $1800 \mathrm{~cm}^{-1}$ in the spectrum of cis-DINGU+Mg are the carbonyl $\mathrm{C}=\mathrm{O}$ stretchings. It occurs at $1617 \mathrm{~cm}^{-1}$ in the case of cis-DINGU+2Mg. Carbonyl stretchings of isomer-A+Mg happens at $1896 \mathrm{~cm}^{-1}$ and $1810 \mathrm{~cm}^{-1}$. The sharp peaks of cisDINGU+Mg', occurring at 1834 and $1684 \mathrm{~cm}^{-1}$ are the carbonyl $\mathrm{C}=\mathrm{O}$ stretchings. In the spectrum of isomer- $\mathrm{B}+\mathrm{Mg}$ the $\mathrm{C}=\mathrm{O}$ stretching occurs at $1864 \mathrm{~cm}^{-1}$. In all the cases peaks above $3500 \mathrm{~cm}^{-1}$ belong to $\mathrm{N}-\mathrm{H}$ stretchings. 

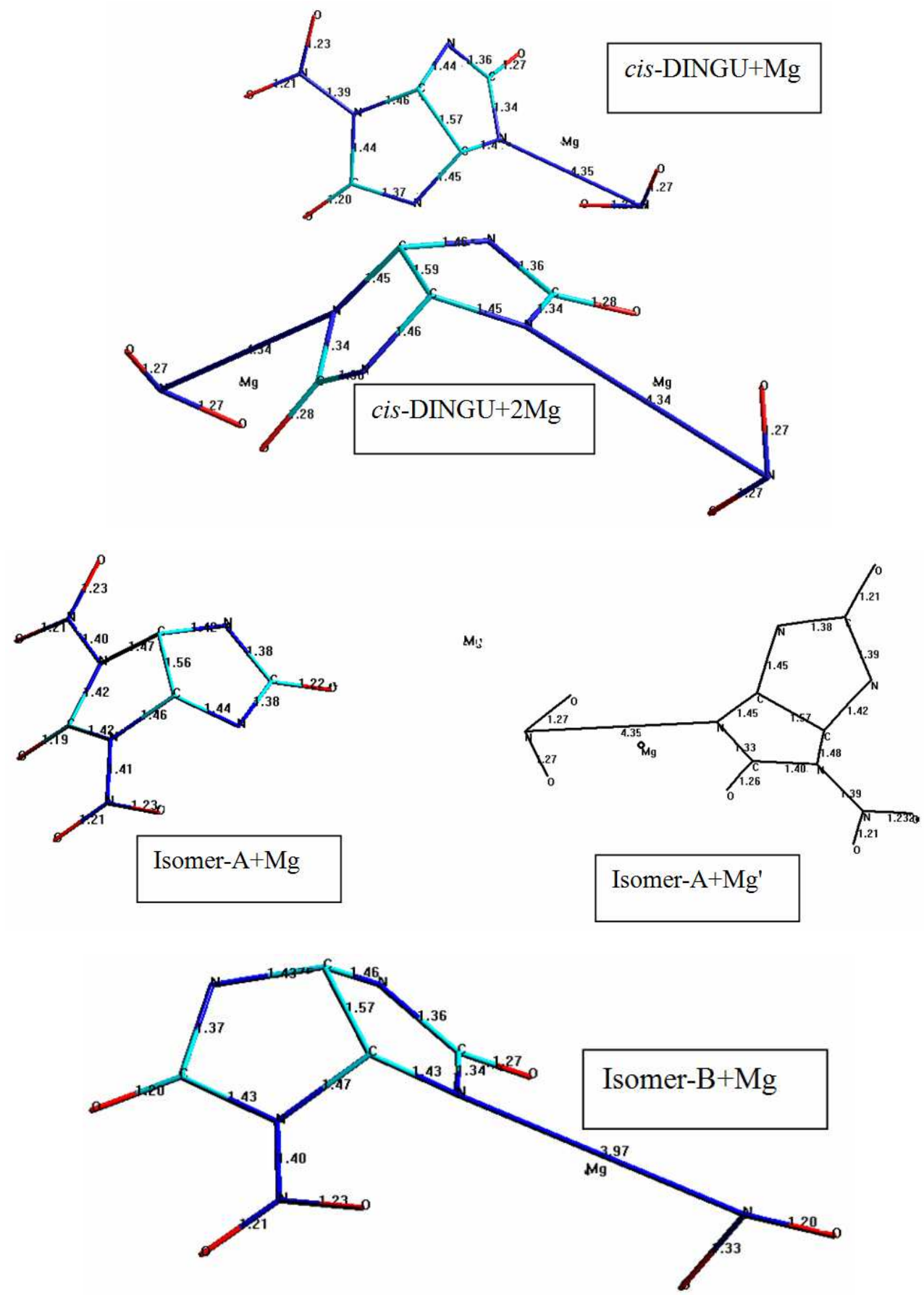

Figure 3. Bond lengths/distances $(\AA)$ in the structures considered (hydrogens omitted). 

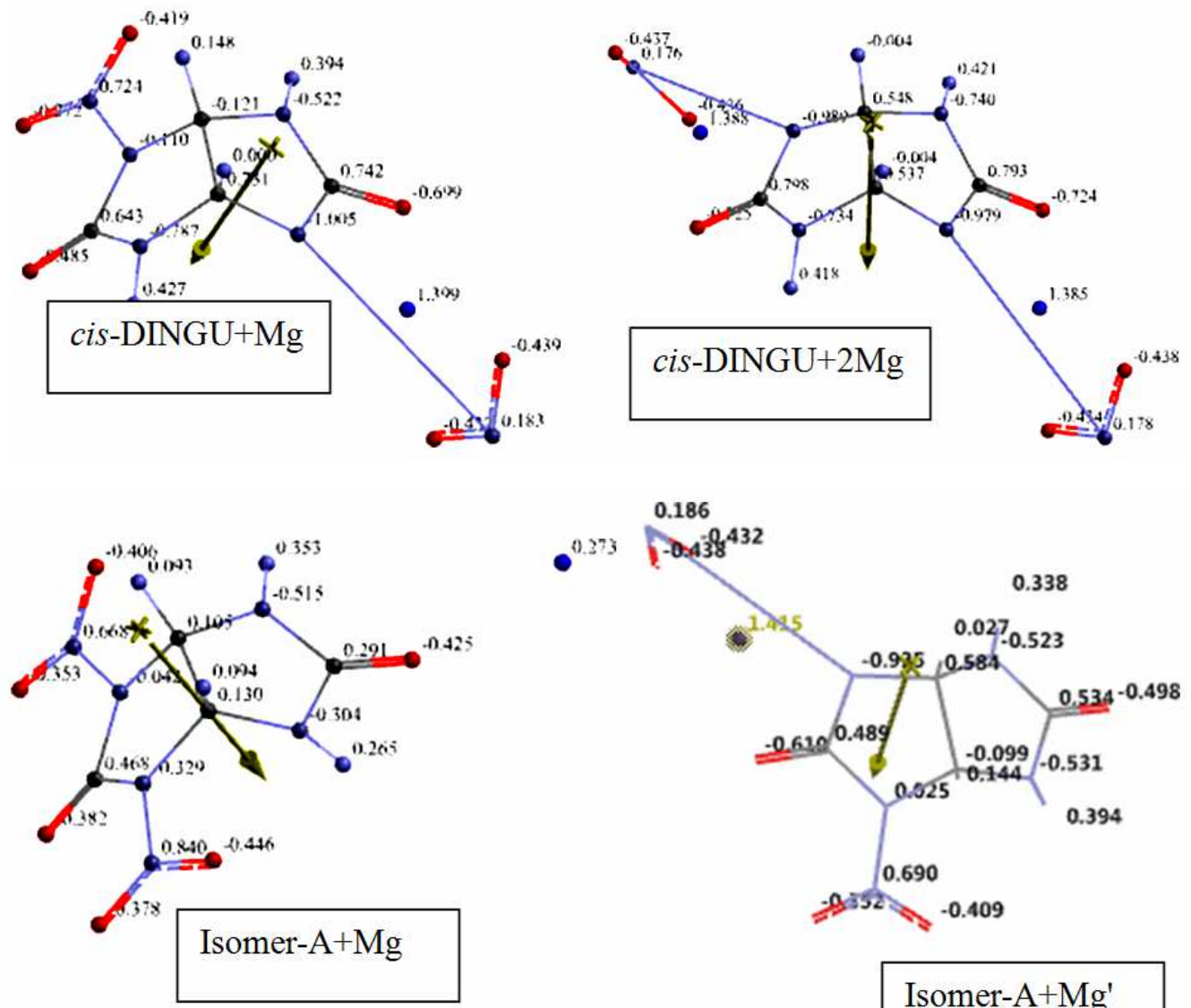

Isomer- $\mathrm{A}+\mathrm{Mg}^{\prime}$

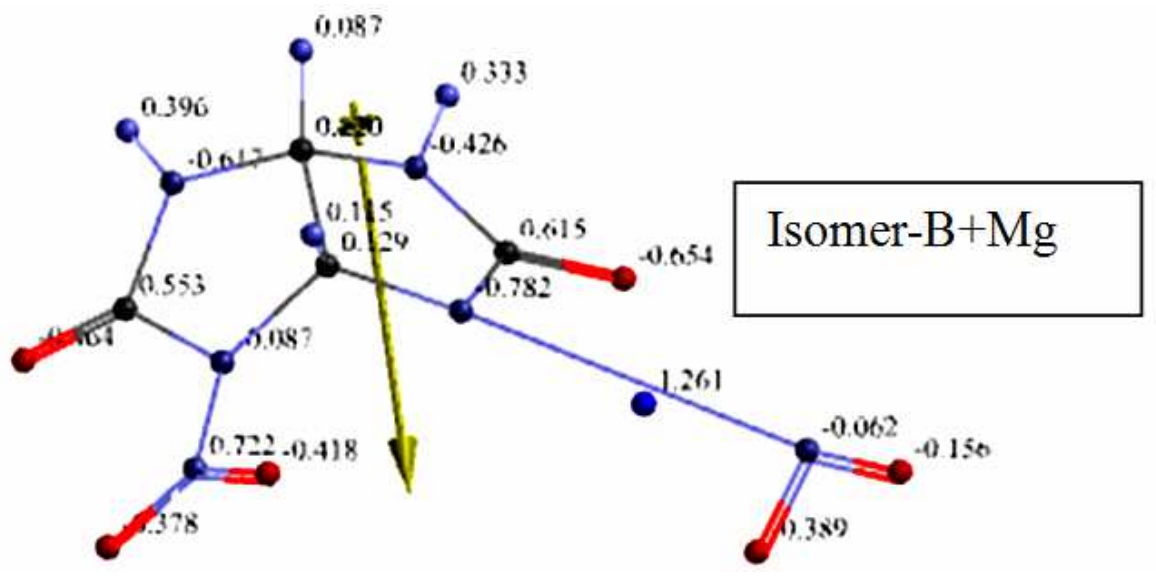

Figure 4. ESP charges on the atoms of the structures considered. 

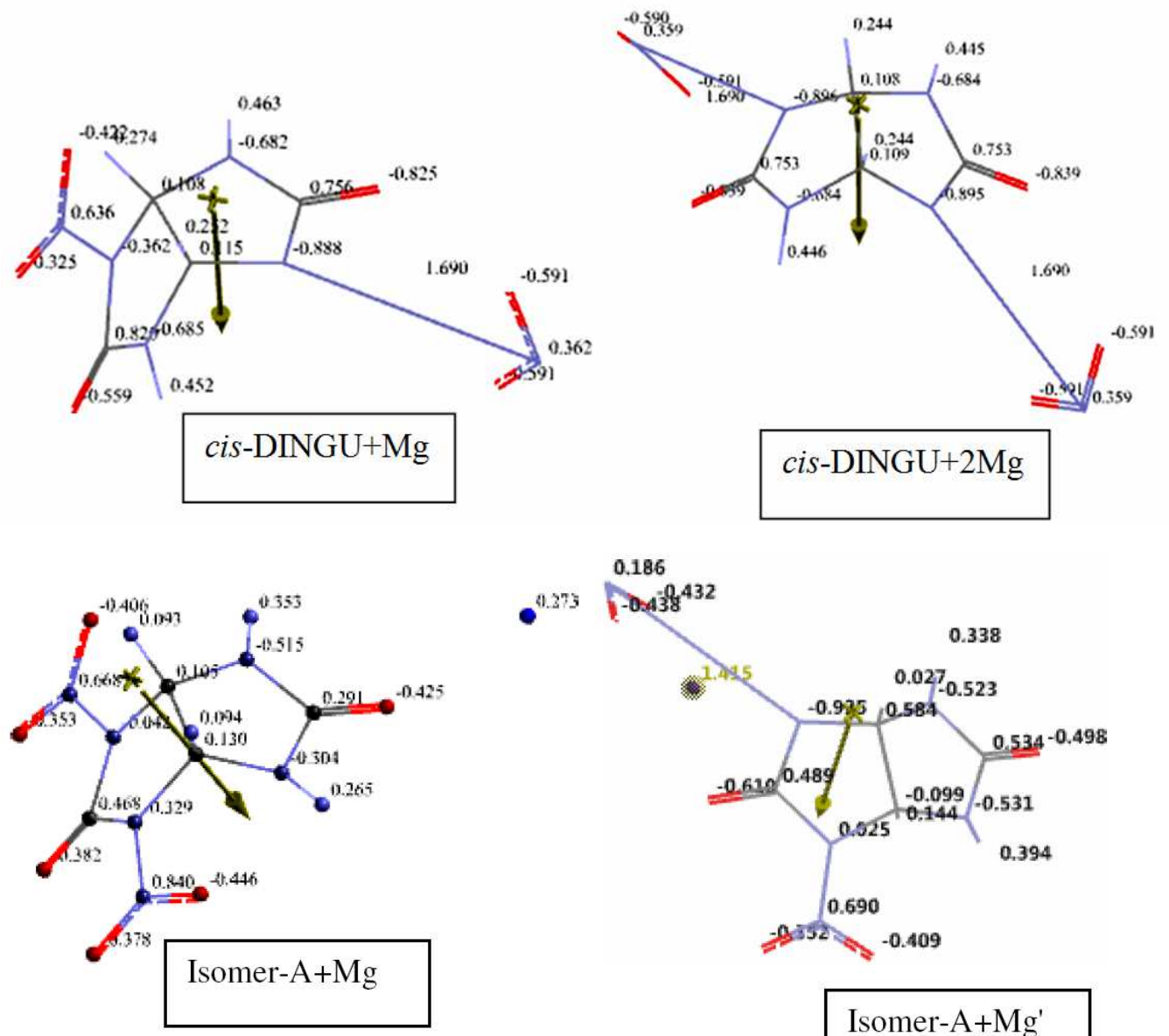

0.186
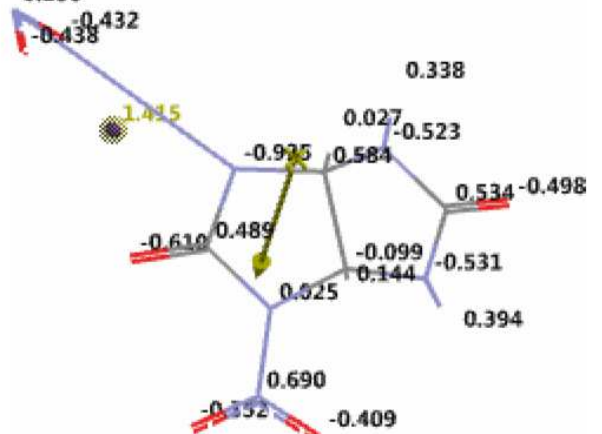

Isomer- $\mathrm{A}+\mathrm{Mg}^{\prime}$

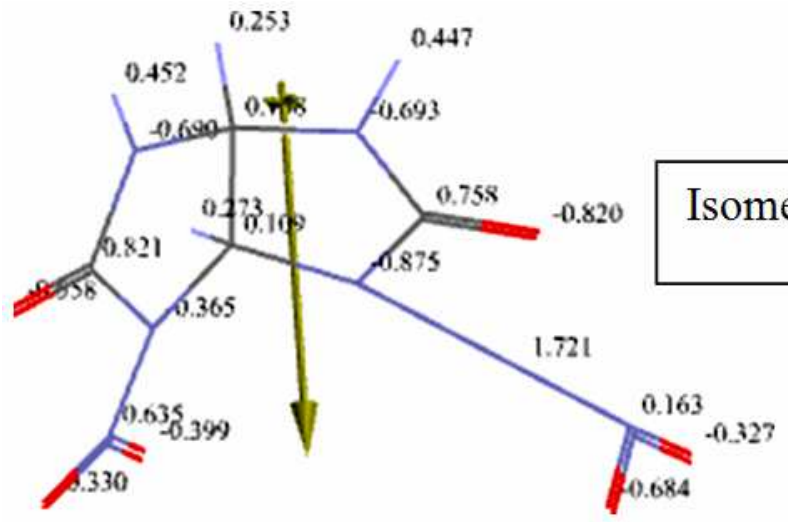

Figure 5. Natural charges on the atoms of the structures considered. 

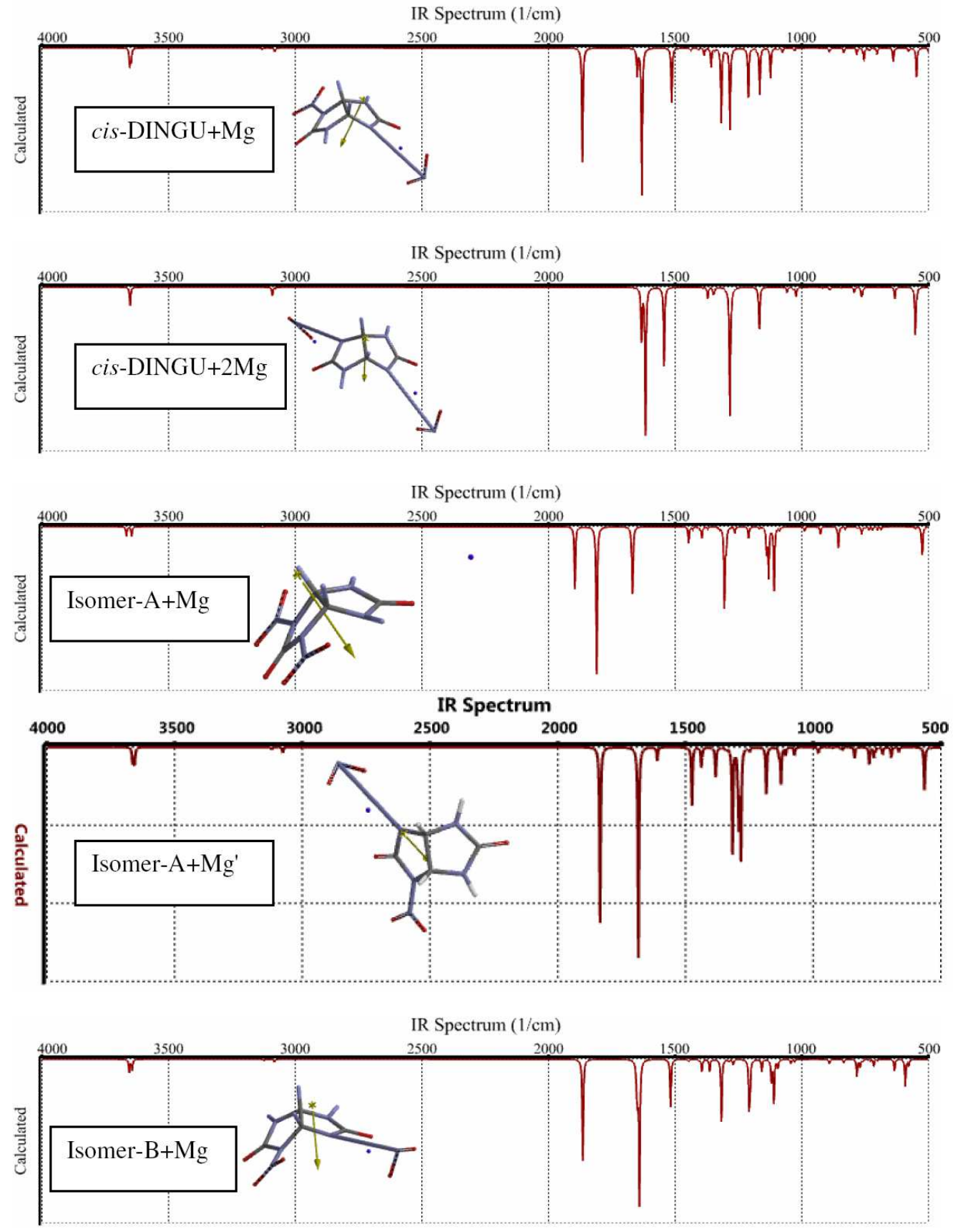

Figure 6. IR spectra of the composites considered. 
Table 1 tabulates some properties of the composites considered. The relatively high dipole moment value for isomer- $\mathrm{B}+\mathrm{Mg}$ case is noticeable.

Table 1. Some properties of the composites considered.

\begin{tabular}{lccc}
\hline Structure & $\begin{array}{c}\text { Dipole moment } \\
\text { (Debye) }\end{array}$ & Ovality & Polarizability \\
\hline cis-DINGU+Mg & 4.42 & 1.43 & 54.59 \\
cis-DINGU+2Mg & 3.65 & 1.51 & 55.68 \\
Isomer-A+Mg & 3.72 & 1.44 & 55.34 \\
Isomer-A+Mg' & 3.93 & 1.44 & 54.61 \\
Isomer-B+Mg & 9.13 & 1.44 & 54.64 \\
\hline
\end{tabular}

$\mathrm{C}_{4} \mathrm{H}_{4} \mathrm{~N}_{6} \mathrm{O}_{6} \cdot \mathrm{Mg}(\mathrm{Mw}: 256.417), \mathrm{C}_{4} \mathrm{H}_{4} \mathrm{~N}_{6} \mathrm{O}_{6} \cdot 2 \mathrm{Mg}(\mathrm{MW}: 280.722)$

All belong to $\mathrm{C} 1$ point group.

Table 2 lists some of the energies of the composites presently considered where E, $\mathrm{ZPE}$ and $\mathrm{E}_{\mathrm{c}}$ are the total electronic energy, zero point vibrational energy and the corrected total electronic energy, respectively. According to the data in the table, the

Table 2. Some energies of the composites.

\begin{tabular}{llll}
\hline Composite & $\mathbf{E}$ & $\mathbf{Z P E}$ & $\mathbf{E}_{\mathbf{c}}$ \\
\hline cis-DINGU+Mg & -2979363.10 & 327.26 & -2979035.84 \\
cis-DINGU+2Mg & -3505147.17 & 324.26 & -3504822.91 \\
Isomer-A+Mg & -2978872.76 & 331.01 & -2978541.752 \\
Isomer-A+Mg' & -2979357.10 & 326.56 & -2979030.535 \\
Isomer-B+Mg & -2979297.92 & 325.75 & -2978972.17 \\
\hline
\end{tabular}

B3LYP/ 6-31++G(D,P) level. In kJ/mol.

stabilities of the systems containing only a single $\mathrm{Mg}$ atom follows the order of cis$\mathrm{DINGU}+\mathrm{Mg}>$ Isomer-A+Mg' > Isomer-B+Mg > Isomer-A+Mg. The stability order of these composites having the same burutto formula should arise not only from the entropy 
factor contribution but also stabilization of the charges and ionic attractions present between the decomposed organic components and partially positively charged $\mathrm{Mg}$ atom.

Table 3 shows the HOMO, LUMO energies and the interfrontier molecular orbital energy gaps $(\Delta \varepsilon)$ of the composites.

Table 3. The HOMO, LUMO energies and the interfrontier molecular orbital energy gaps $(\Delta \varepsilon)$.

\begin{tabular}{lccc}
\hline Composite & HOMO & LUMO & $\Delta \boldsymbol{\varepsilon}$ \\
\hline cis-DINGU+Mg & -751.76 & -273.38 & 478.37 \\
cis-DINGU+2Mg & -703.75 & -256.96 & 446.78 \\
Isomer-A+Mg & -449.61 & -345.13 & 104.48 \\
Isomer-A+Mg' & -763.19 & -285.63 & 477.57 \\
Isomer-B+Mg & -713.50 & -245.86 & 467.64 \\
\hline
\end{tabular}

B3LYP/ 6-31++G(D,P) level. In kJ/mol.

Variation of the energies from one system to another in Table 3 arises from structural peculiarities of the organic component present in the optimized composites which is most of the cases a decomposed structure. Isomer- $\mathrm{A}+\mathrm{Mg}$ has the smallest interfrontier molecular orbital energy gap $(\Delta \varepsilon)$. Note that it is not decomposed composite however it is less stable system as compared to isomer- $\mathrm{A}+\mathrm{Mg}$ (see Table 2).

Figure 7 shows some of the molecular orbital energy levels of the composites.

\section{Conclusion}

The present modeling study, within the constraints of DFT and the level of calculations performed reveals that cis-DINGU and its constitutional nitramine isomers are incompatible with magnesium. The metal transfers some electron population to the organic component causing the cleavage of $\mathrm{N}-\mathrm{NO}_{2}$ bond. The expelled $\mathrm{NO}_{2}$ moiety and the remnant of the organic component possess some partial negative while the magnesium acquires the opposite charge. 

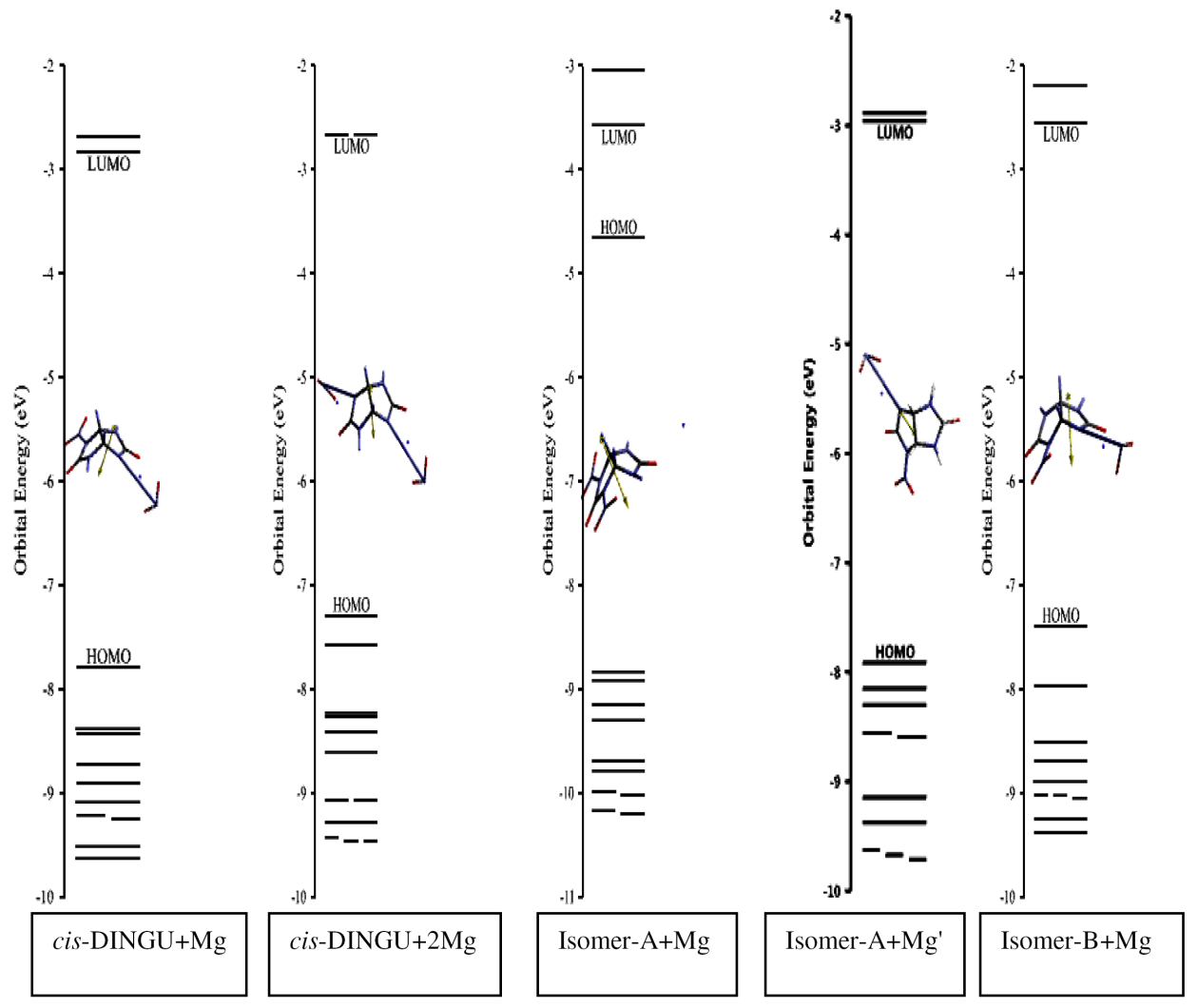

Figure 7. Some of the molecular orbital energy levels of the composites.

\section{References}

[1] J. Boileau, M. Carail, E. Wimmer, R. Gallo and M. Pierrot, Acetylated nitro derivatives of glycoluril, Propell. Explos. Pyrotech. 10 (1985) 118-120.

https://doi.org/10.1002/prep.19850100407

[2] K. Cui, G. Xu, Z. Xu, P. Wang, M. Xue, Z. Meng, J. Li, B. Wang, Z. Ge and G. Qin, Synthesis and characterization of a thermally and hydrolytically stable energetic material based on N-nitrourea, Prop. Explos. Pyrotech. 39(5) (2014), 662-669. https://doi.org/10.1002/prep.201300100

[3] J. Boileau, J. M. L. Emeury and J. P. Kehren, Tetranitroglycoluril and method of preparation thereof, Ger. Offen. 2462330; Chem. Abstr., 1977, 86, P75499.

[4] A. P. N. Franchimont and E. A. Klobbie, Quelques nitramines et leur préparation, Recl. Trav. Chim. 7(12) (1888), 343-357. https://doi.org/10.1002/recl.18880071204 
[5] A. P. N. Franchimont and E. A. Klobbie, Contributions à la connaissance de l'action de l'acide azotique sur les corps organiques, Recl. Trav. Chim. 8(10) (1889), 283-292. https://doi.org/10.1002/recl.18890081001

[6] J. Boileau, E. Wimmer, M. Carail and R. Gallo, Preparation of nitro and nitroacetyl of glycouril, Bulletin de la Societe Chimique de France 3 (1986), 465-469.

[7] M. N. Zharkov, I. V. Kuchurov, I. V. Fomenkov, S. G. Zlotin and V. A. Tartakovsky, Nitration of glycoluril derivatives in liquid carbon dioxide, Mendeleev Commun. 25 (2015), 15-16. https://doi.org/10.1016/j.mencom.2015.01.004

[8] J. Boileau, J. M. Emeury, Y. De Longueville and P. Monteagudo, Dinitroglycolurile and sorguyl-preparations properties, Chem. Mech. Technol. Treib-Explos. (1981), 505-526.

[9] L. Jiamin, The LOVA composite explosives containing DINGU, Proceedings of the Seventeenth International Pyrotechnich Seminar Combined with Second Beijing International Symposium on Pyrotechnics and Explosives, 1, Beijing, 1992, pp. 322-332.

[10] J. P. Agrawal, Recent trends in high-energy materials, Prog. Energy Combust. Sci. 24 (1998), 1-30. https://doi.org/10.1016/S0360-1285(97)00015-4

[11] A. K. Sikder and N. Sikder, A review of advanced high performance, insensitive and thermally stable energetic materials emerging for military and space, J. Hazard. Mater. A 112 (2004), 1-15. https://doi.org/10.1016/j.jhazmat.2004.04.003

[12] J. E. London and D. M. Smith, Toxicological study of the high-explosive formulation imidazo[4,5-d]imidazole-2,5(1H,3H)-dione, tetrahydro-1,4-dinitro, Avail. NTIS. Rep. 9 (14) (1984) (Abstract no. 26903).

[13] J. Boileau, E. Wimmer, R. Gilardi, M. M. Stinecipher, R. Galio and M. Pierrot, Structure of 1,4-dinitroglycoluril, Acta Crystallogr. 44 (1988), 696-699.

https://doi.org/10.1107/S0108270187012204

[14] D. Mathieu and P. Simonetti, Evaluation of solid-state formation enthalpies for energetic materials and related compounds, Thermochim. Acta 384 (2002), 369-375.

https://doi.org/10.1016/S0040-6031(01)00795-X

[15] V. H. Khire, M. B. Talawar, K. V. Prabhakaran, T. Mukundan and E. M. Kurian, Spectrothermal decomposition study of 1,4-dinitroglycoluril (DINGU), J. Hazard. Mater. A 119 (2005), 63-68. https://doi.org/10.1016/j.jhazmat.2004.12.020

[16] J. Yinon, S. Bulusu and T. Axenrod, Mass spectral fragmentation pathways in some glycoluril-type explosives. A study by collision-induced dissociation and isotope labeling, Org. Mass Spectrom. 29(11) (1994), 625-631. https://doi.org/10.1002/oms.1210291109 
[17] D. Delpeyroux, B. Blaive, R. Gallo, H. Graindorge and L. Lescop, Modelization by molecular mechanics (and X-rays) of five-membered heterocyclic nitramines, Propell. Explos. Pyrotech. 19(2) (1994), 70-75. https://doi.org/10.1002/prep.19940190203

[18] D. Paz, J. G. Luis and J. Ciller, On the use of AM1 and PM3 methods on energetic compounds, Propell. Explos. Pyrotech. 18(1) (1993), 33-40.

https://doi.org/10.1002/prep.19930180107

[19] L. Türker and T. Atalar, Ab initio and DFT study on 1,4-dinitroglycoluril configurational isomers: cis-DINGU and trans-DINGU, Journal of Hazardous Materials A137 (2006), 47-56. https://doi.org/10.1016/j.jhazmat.2006.01.060

[20] L. Türker, Trans-dinitroglycoluril isomers-A DFT treatment, Defence Technology 13(1) (2017), 6-15. https://doi.org/10.1016/j.dt.2016.12.002

[21] A. R. Leach, Molecular Modeling, Essex: Longman, 1997.

[22] P. Fletcher, Practical Methods of Optimization, New York: Wiley, 1990.

[23] W. Kohn and L. Sham, Self-consistent equations including exchange and correlation effects, J. Phys. Rev. 140 (1965), 1133-1138. https://doi.org/10.1103/PhysRev.140.A1133

[24] R. G. Parr and W. Yang, Density Functional Theory of Atoms and Molecules, London: Oxford University Press, 1989.

[25] A. D. Becke, Density-functional exchange-energy approximation with correct asymptotic behavior, Phys. Rev. A 38 (1988), 3098-3100. https://doi.org/10.1103/PhysRevA.38.3098

[26] S. H. Vosko, L. Wilk and M. Nusair, Accurate spin-dependent electron liquid correlation energies for local spin density calculations: a critical analysis, Can. J. Phys. 58 (1980), 1200-1211. https://doi.org/10.1139/p80-159

[27] C. Lee, W. Yang and R. G. Parr, Development of the Colle-Salvetti correlation-energy formula into a functional of the electron density, Phys. Rev. B 37 (1988), 785-789. https://doi.org/10.1103/PhysRevB.37.785

[28] SPARTAN 06, Wavefunction Inc., Irvine CA, USA, 2006.

[29] R. O. C. Norman, Principles of Organic Synthesis, London: Methuen, 1970.

[30] P. J. Durant and B. Durant, Introduction to Advanced Inorganic Chemistry, London: Longman, 1972. 